\title{
A Smart Home with NodeMCU using IOT
}

\author{
Roshni Bhandari \\ Assistant Professor \\ Computer Engineering Department \\ S.S.Agrawal Institute of \\ Engineering and Technology \\ Navsari, India
}

\author{
Patel Darshan M. \\ Student Computer Engineering \\ Department \\ S.S.Agrawal Institute of Engineering \\ and Technology \\ Navsari, India
}

\author{
Dhimar Richi K. \\ Student \\ Computer Engineering Department \\ S.S.Agrawal Institute of Engineering \\ and Technology \\ Navsari, India
}

\author{
Patel Keyur D. \\ Student \\ Computer Engineering Department \\ S.S.Agrawal Institute of Engineering and Technology \\ Navsari, India
}

\begin{abstract}
IOT is now a days most preferred technology. A system of interrelated computing devices, mechanical and digital machines, objects, animals or people that are provided with unique identifiers (UIDs) and the ability to transfer data over a network without requiring human-to-human or human-tocomputer interaction. One of the major sides of IOT is a smart home. Smart home is very helpful for the peoples to make life easy. Home Automation is the automatic or semi- automatic control and monitoring of household appliances and residential house features like doors, Gate, light, fans and even the windows. The IOT definition has been evolved due to convergence of multiple technologies like, The Real Time Analysis, Machine Learning, Commodities Sensors and Embedded systems. IOT technology is used more for making the home to asmart home.
\end{abstract}

\section{General Terms}

Smart home, NodeMCU, Home Automation

\section{Keywords}

Home automation, NodeMCU ,ESP2866 WI-FI module , Relay, website, Android Application, Smartphone.

\section{INTRODUCTION}

The internet of things, or IOT, is a system of interrelated computing devices, mechanical and digital machines, objects, animals or people that are provided with unique identifiers (UIDs) and the ability to transfer data over a network without requiring human-to-human or human-to-computer interaction[8]. One of the major sides of IOT is a smart home. The era of never-ending growth of the internet and its application, smart home system or home automation system is highly increasing to provide comfort in life and improving the quality of life.

In this paper, an IOT based low-cost smart home automation system is proposed. The main objective of this system is to make human life easy and comfortable by using IOT. Now a day as people are so busy with their work pressure so the will be looking for a smarter life style[7].

Home automation or domotics is building automation for a home, called a smart home or smart house. A home automation system will control lighting, climate, entertainment systems, and appliances. It may also include home security such as access control and alarm systems[6]. A home automation system typically connects controlled devices to a central hub.

\section{LITERATURE SURVEY}

In developed and developing countries the more and more technologies are arriving every year. And of the most important is the IOT. IOT can be used in many sectors of the technology. IOT is also used in home automation which helps to make life easy as well as it is time saving. Smartphone Application can be utilize for the IOT communication protocols. Application can be used to monitor and control local switches via mobile phone. Many systems are reported in the literature based on single monitoring and controlling mode utilizing text, voice or gesture commands. The system has two different operation modes first mode make use of a mobile app interface with virtual switches and slider to monitor and control appliances. The second is chat-based that use text or audio command filter with natural language processing to monitor and control the home appliances. The proposed system is scalable in that it is able to add and remove rooms on demand. Most of the technologies which are in the developed are limited as some as feature of turning light and fan on and off while some has control over the gate. There is one technology in which website is use to control the home appliances and in another one there is only mobile application. Different technologies are developed in different way[1].

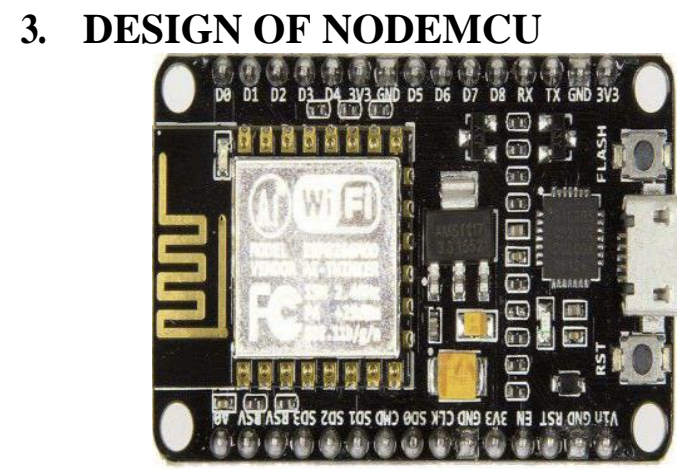

Fig-1:NodeMCU[5]

Node MCU is an open source IOT platform. It includes firmware which runs on the ESP8266 Wi- Fi SoC from 
Espress if Systems, and hardware[ which is based on the ESP12 module. The term "NodeMCU" by default refers to the firmware rather than the dev kits. The firmware uses the Lua scripting language. It is based on the eLua project, and built on the Espress if Non-OS SDK for ESP8266. The ESP8266 is a Wi-Fi SoC integrated with a Tensilica Xtensa LX106 core, widely used in IoT applications.[3]

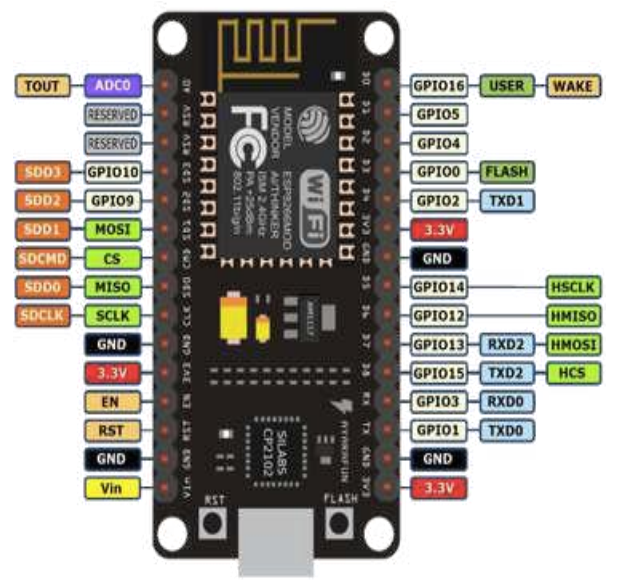

Fig-2:Pin config[3]

While writing GPIO code on NodeMCU, you can't address them with actual GPIO Pin Numbers as shown in Figure. There are different I/O Index numbers assigned to each GPIO Pin which is used for GPIO Pin addressing. ESP8266EX offers a complete and self- contained WIFI networking solution; it can be used to host the application or float WIFI networking functions from another application processor. When ESP8266EX hosts the application, it boots up directly from an external flash. In has integrated cache to improve the performance of the system in such applications[3].

\section{PROPOSED ALGORITHM}

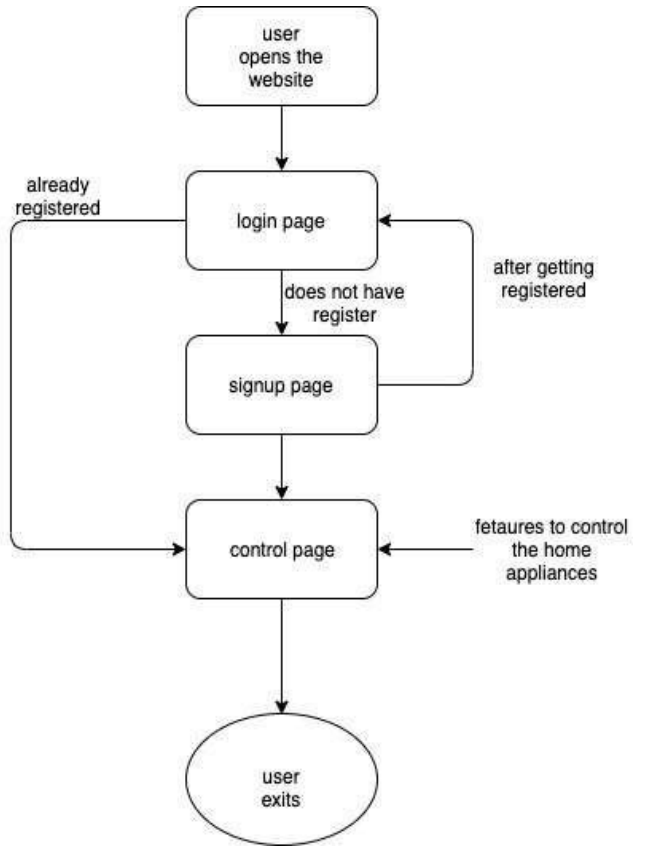

Fig-3:Algorithm of System

The above mentioned algorithm is used for system. In this system, first the user has to login if the user is not registered then user will register and then again user will login and then user will be redirected to the page where all the control will be given like button to turn on and off the light and fan and other feature controls are given after using it user will quit.

Features:

- Turning light on and off.

- Turning fan on andoff.

- Door lock system.

\section{IMPLEMENTATION \\ 5.1 Login Page}

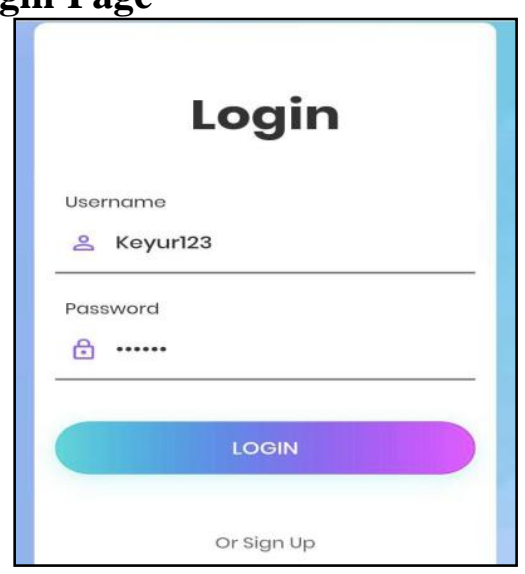

Fig-4: login page

The user has to login as for the authentication of the user. Once the user is logged in successfully the server of the NodeMCU will be provided to the user where the user can operate and control the appliances.

\subsection{Control page with working}

- When switch ison:

- he light gets turned on and when pressing on button the fan getsstart.

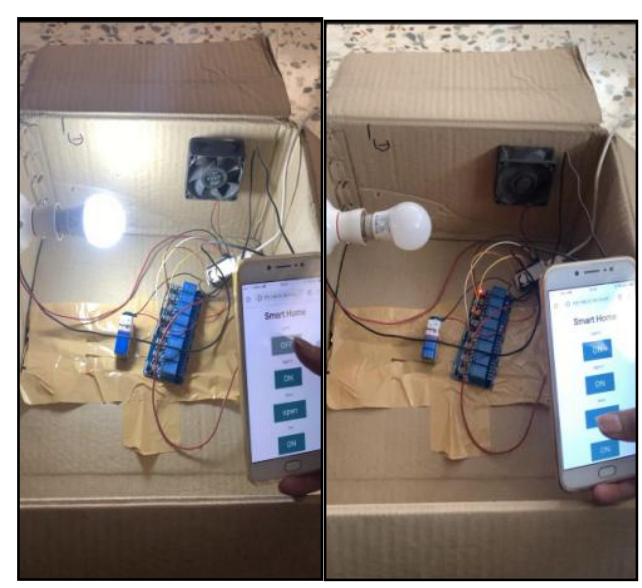

Fig-5 Light on

Fig-6 Light off

- When switch is off:

- The fan gets off when the off button is pressed. 


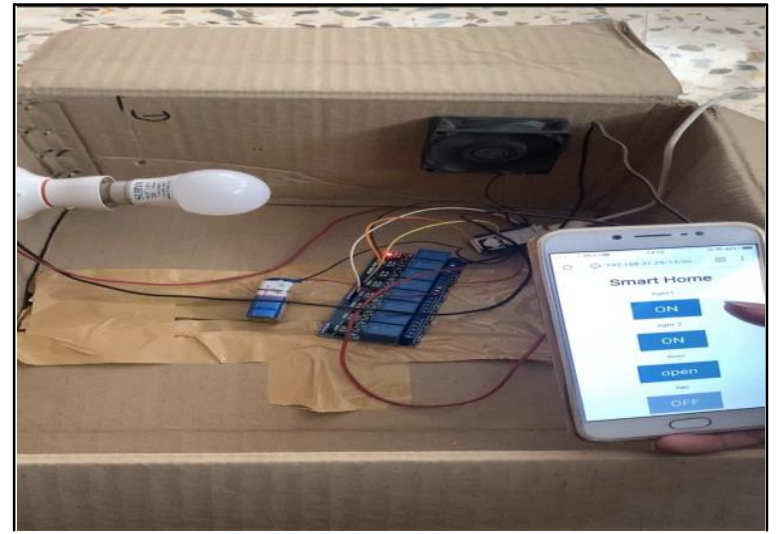

Fig-7 Fan control system

- The Door Locking System:

The door is opened and close by pressing the buttons on and off. It is done because of the motor which will push and pull the rod to open and close the door. The motor is connected to the NodeMCU at pin D6/GPIO 12.

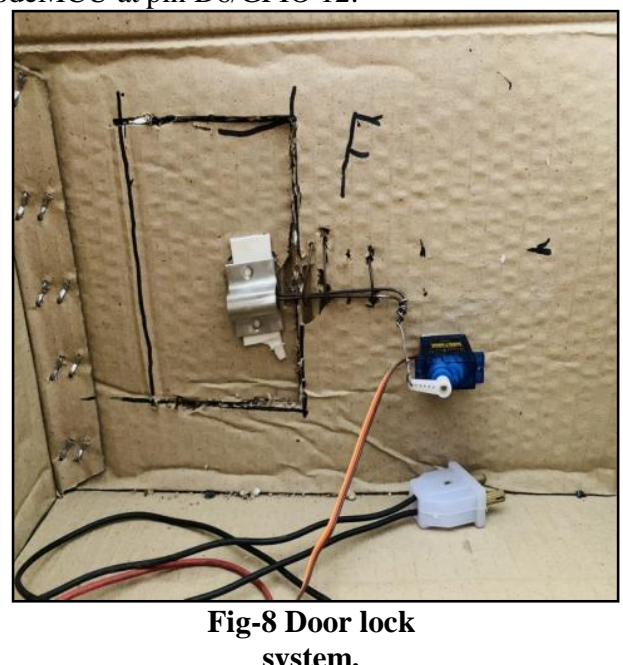

5.3 The system that will control all features is

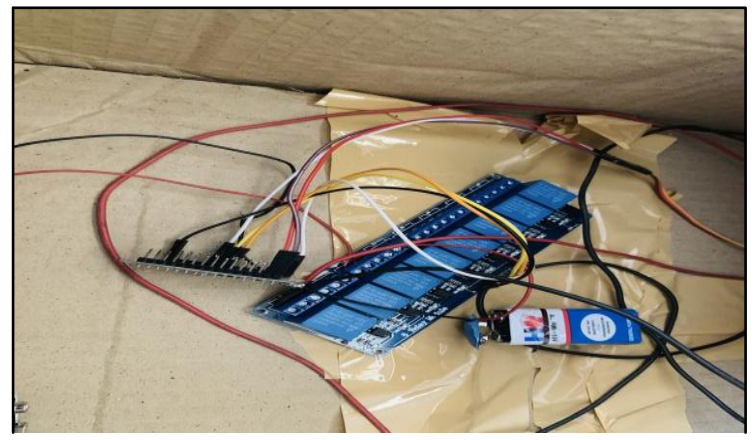

Fig-9 Home Control System
The main controller is the NodeMCU and it is connected to the 8 channel relay which is used to control the home appliances. It used to control the supply of voltage. By using this AC supply can also control for the appliances. It will start passing the voltage when the button is pressed and the appliance will start working. One of the wire is connected to the AC supply and another common one is connected to the AC supply and also with the relay. Below Figure-10 is the 8 channel relay that is used in the system.

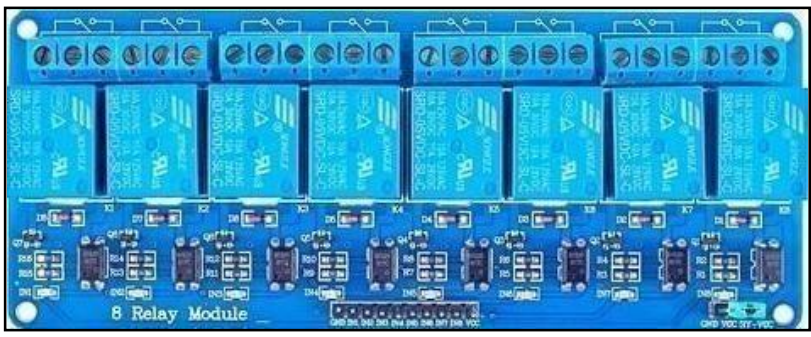

Fig-10 8 channel relay[5]

\section{CONCLUSION AND FUTURE WORK}

In this paper, we have designed an advanced automation system which has features like turning light and fan on and off, door security which in turn reduces most of the human interactions, by supporting this system using Internet of Things (IoT).It is an inexpensive system. It can be associated with various other options like energy monitoring systems , surveillance system, biometric access etc., soon, as an extension to this project a system may be developed which warns the user about the excess usage of energy and excess amount of water flowing.

\section{REFERENCES}

[1] Survey on IOT based Home Automation-ijca , Roshni Bhandari, Dhimar Richi, Patel Darshan , Patel Keyur, October 2019.

[2] A Smart Home Automation technique with Raspberry Pi using IoT ,IEEE, Vamsikrishna Patchava , Hari Babu Kandala , P Ravi Babu., 2015.

[3] IOT Based Home Electrical Appliances Control Using Node MCU, M. SaiKrishna, G.Vijaykiran, February 2017.

[4] https://randomnerdtutorials.com/esp8266-web-server/ how to create webserver.

[5] Home Automation using Arduino, Dr. S.Manju, K. Charsukesini, January-2020.

[6] https://en.wikipedia.org/wiki/Home_automation

[7] https://ieeexplore.ieee.org/document/8644349

[8] https://internetofthingsagenda.techtarget.com/definition/In ternet-of-Things-IoT 